\section{Secondary School Students Awareness and Attitudes Towards Mental Health Disorders in Bayelsa State, Nigeria}

\section{Abstract}

The stigma associated with mental disorders can have a considerable impact on several aspects on the affected persons and their families. The study aimed to assess secondary school students' awareness and attitude towards mental health disorders. An analytical descriptive survey design was used to collect data from five public secondary schools in the Local Government Area of Bayelsa State, Nigeria. 195 senior secondary schools students in level three (SSS III) (representing 26 percent) of the total population were selected through proportionate stratified random sampling technique. Results show that $61 \%$ have little or no awareness on types of information, and $75 \%$ on sources of information. While both positive and negative attitude towards mental health disorders exist, students' with positive attitude differ significantly from those with negative attitude. The need for training program to target this receptive population in the belief that improving their perception of mental health disorder will discourage the stigma associated with the disorder, and dispel the associated fear and false beliefs.

Keywords: Awareness; Education; Information; Mental health disorder; Perception; Secondary school students
Izibeloko Omi Jack-ide

Department of Mental Health, Niger Delta University, Wilberforce Island, Nigeria

\section{Corresponding author: Izibeloko Omi Jack-ide}

\section{}

Niger Delta University, Wilberforce Island, Nigeria.

Tel: +234809757544

Citation: Jack-ide IO. Secondary School Students Awareness and Attitudes Towards Mental Health Disorders in Bayelsa State, Nigeria. Ann of Behav Sci. 2016, 2:1.

\section{Introduction}

Mental health disorder has been reported as one of the biggest challenges facing every country, including Nigeria, with young people considered to be especially at risk [1]. Evidence shows that mental health problems are common in adolescents, with approximately one in five experiencing some form of emotional disorder [2-4]. Findings from Kessler et al. [5] reveal that $50 \%$ of all lifelong mental health disorders start by age 14 and $75 \%$ by age 24 . In many societies worldwide, despite growing evidence of the importance of mental health to ensure economic, social and human capital, negative perceptions continue to be associated with mental health disorders and the associated mental health services and professionals $[6,7]$. The public perceptions that people with mental health disorders cannot be employed or maintain their jobs, live independently, or build long-term relationships is widespread [8-10]. These misconceptions can impact on individuals living with disorders that results in poor follow-up care and recovery [6,11], and further deepens the stigma and discrimination [12]. Research has shown that prognosis for mental health disorders can improve through early detection and intervention $[13,14]$. Addressing discrimination and stigma needs to occur both formally and informally, specifically among children and young adults, some of whom will one day need to make use of such services.

Naylor et al. [15] argue that educating young people in secondary schools about mental health disorders not only affects their understanding of mental health but that their family, friends and neighbors. In addition, research shows that programs aiming at increasing young people's knowledge of mental health through contact and education have shown positive results in reducing negative attitudes towards people with such disorders [16,17]. A study [6] found that prejudice about mental health disorders was mainly due to ignorance, and that people who are knowledgeable about such disorders are less likely to endorse negative attitude. A study [18] confirmed that members of the public who have contact with persons suffering with mental disorders are less likely to endorse stigmatizing attitudes. Education is therefore a strong tool for enhancing knowledge and reducing negative attitudes towards mental health disorders [15].

Research on young people's views of mental health disorders show positive changes after exposure to educational programs. A study [19] on awareness and education about mental health 
disorders in teenagers reported that the students showed a significant reduction of stigma after acquiring new information about such conditions. In another study [20] on changing attitude of high school students towards peer with mental health disorders revealed positive changes in their attitudes, and that discrimination and the tendency towards social restriction were reduced six months after an attitudinal change program was implemented. Furthermore, Pinfold et al., [21] confirmed that short educational workshops produced positive change in young people's views of mental health disorders.

A handful of studies have explored attitudes among healthcare students and the effectiveness of training programs in various countries [22,23]. However, there is a paucity of research in the Niger Delta region of Nigeria regarding awareness and attitudes of secondary school students towards mental health disorders. The current study therefore aimed to explore the awareness and attitude of secondary school students towards mental health disorders, so as to indicate the need for attitude-change programs before unhealthy attitudes and beliefs become entrenched.

\section{Methods}

The study adopted an analytical descriptive questionnaire survey design. The study population consisted of 750 students' from five public secondary schools in the Local Government Area of Bayelsa State, Nigeria. A sample size of 195 students' (representing 26\%) was selected through stratified random sampling technique. This consisted of 55, 38, 42, 33 and 27 students from the five public secondary schools. The questionnaire had three sections ( $A$, $B$ and $B$ ) with $A$ obtaining their demographic data, and $B$ and $C$ requiring the selection of options on a 4 point rating scale. Section B sought for types, and C the sources of information and students' awareness and attitude towards mental health disorders. The face, content and construct validity of the instrument were validated by two experts, and the corrections were reflected. To determine the reliability of instrument, it was administered to 20 students of senior secondary school 3 (SSS III) in another Local Government Area within the State, that was not part of the main study through the test-retest method within an interval of two weeks. The scores obtained were subjected to Pearson Product Moment Correlation coefficient (PPMC) analysis, which yielded 0.82 , this value being considered an acceptable reliability coefficient for the study.

The instrument was administered by the researchers and two trained research assistants. The process of distributing and retrieving the questionnaire lasted for three weeks. Ethical approval was provided by the Ministry of Education, and written informed consent was obtained after informing the participants and their parents about the purpose of study. The data was analyzed using descriptive statistics, such as percentage, mean, standard deviation and inferential statistics of t-test analysis. This was done using the Statistical Package for Scientific Solutions (SPSS) IBM version 20.

\section{Results}

Table 1 indicates that less than half were male (43\%). 55\% were 10-15 years of age, most were Christian (95\%), and 56\% were from the ljaw tribe.
Table 2 shows almost $40 \%$ of the students' had no information about mental illness in general, while a similar number (39\%) indicate having some information. Almost half (47\%) indicated having no knowledge of how people cope with mental illness, while less than half ( $37 \%$ ) claimed to be informed. On the different approaches to help persons with mental illness, the majority $(46 \%)$ has no idea, while a third (33\%) has some information, only a few (10\%) indicated that they knew what it was like to have a mental illness, while almost half (59\%) had no ideal. In terms of the overall mean score regarding their knowledge about types of information, the $61 \%$ (None and A-Little) had little or no information, while $39 \%$ had some information about mental disorders.

Table 3 shows the results regarding the sources of information about mental health disorder, and indicates that over half $(57 \%)$ received a lot of information from teachers, while movies, radio/television were an important source of information, as were friends/family, with print and electronic media making a significant contribution. Regarding the total mean, 75\% (Some and $A$ lot) had more sources of information, while $25 \%$ (None and $A$ Little) had less access to information about mental health disorders.

Table 4 shows that majority (79\%) agreed that most people with mental illness can get well and return to productive lives with treatment. Less than half $(45 \%)$ agreed that the community helps people with mental illness get better. The majority (62\%) disagreed that people with mental illness are far less of a danger

Table 1 Demographic data of respondents $(n=179)$.

\begin{tabular}{|c|c|c|c|}
\hline Variable & Category & N & $\%$ \\
\hline \multirow{2}{*}{ Gender } & Male & 83 & 43 \\
\hline \multirow{3}{*}{ Age (years) } & Female & 112 & 57 \\
\hline \multirow{2}{*}{ Religion } & $10-15$ & 107 & 55 \\
\hline \multirow{2}{*}{$*$} & $16-20$ & 83 & 43 \\
\hline \multirow{2}{*}{ Tribe } & $21-25$ & 5 & 2 \\
\hline & Christian & 186 & 95 \\
\hline & Muslim & 9 & 5 \\
\hline & Ijaw & 110 & 56 \\
\hline & Igbo & 32 & 16 \\
\hline & Yoruba & 7 & 4 \\
\hline & Hausa & 2 & 1 \\
\hline & Others & 44 & 23 \\
\hline
\end{tabular}

Table 2 Types of information about mental health disorders $(n=195)$.

\begin{tabular}{|c|c|c|c|c|c|}
\hline S/no. & Types of Information & $\begin{array}{l}\text { None } \\
\text { No \% }\end{array}$ & $\begin{array}{l}\text { A little } \\
\text { No } \%\end{array}$ & $\begin{array}{l}\text { Some } \\
\text { No \% }\end{array}$ & $\begin{array}{l}\text { A lot } \\
\text { No } \%\end{array}$ \\
\hline 1 & Mental illness in general & $\begin{array}{c}79 \\
(40)\end{array}$ & $\begin{array}{c}27 \\
(14)\end{array}$ & $\begin{array}{c}76 \\
(39)\end{array}$ & $\begin{array}{l}13 \\
(7)\end{array}$ \\
\hline 2 & $\begin{array}{l}\text { How people cope with mental } \\
\text { disorders }\end{array}$ & $\begin{array}{c}91 \\
(47)\end{array}$ & $\begin{array}{c}25 \\
(13)\end{array}$ & $\begin{array}{c}73 \\
(37)\end{array}$ & $\begin{array}{c}6 \\
(3)\end{array}$ \\
\hline 3 & $\begin{array}{l}\text { Different approaches to help } \\
\text { persons with mental illness }\end{array}$ & $\begin{array}{c}90 \\
(46)\end{array}$ & $\begin{array}{c}28 \\
(14)\end{array}$ & $\begin{array}{c}64 \\
(33)\end{array}$ & $\begin{array}{l}13 \\
(7)\end{array}$ \\
\hline \multirow[t]{2}{*}{4} & $\begin{array}{l}\text { What it is like to have a mental } \\
\text { disorder }\end{array}$ & $\begin{array}{l}115 \\
(59)\end{array}$ & $\begin{array}{l}14 \\
(7)\end{array}$ & $\begin{array}{c}46 \\
(24)\end{array}$ & $\begin{array}{c}20 \\
(10)\end{array}$ \\
\hline & Grand mean & $\begin{array}{c}94 \\
(49)\end{array}$ & $\begin{array}{c}24 \\
(12)\end{array}$ & $\begin{array}{c}65 \\
(33)\end{array}$ & $\begin{array}{l}12 \\
(6)\end{array}$ \\
\hline
\end{tabular}

Cut-off percentage $=50$ 
Table 3 Sources of information about mental health disorders $(n=195)$.

\begin{tabular}{|c|c|c|c|c|c|}
\hline S/no. & Sources of information & $\begin{array}{c}\text { None } \\
\text { No } \%\end{array}$ & $\begin{array}{c}\text { A little } \\
\text { No \% }\end{array}$ & $\begin{array}{c}\text { Some } \\
\text { No } \%\end{array}$ & $\begin{array}{c}\text { A lot } \\
\text { No \% }\end{array}$ \\
\hline $\mathbf{1}$ & Teachers & 23 & 19 & 41 & 112 \\
& $(12)$ & $(10)$ & $(21)$ & $(57)$ \\
\hline \multirow{2}{*}{$\mathbf{2}$} & Movies, radio/television & 33 & 37 & 57 & 68 \\
\hline \multirow{2}{*}{$\mathbf{3}$} & Friends/family/community & $(17)$ & $(19)$ & $(29)$ & $(35)$ \\
\hline \multirow{2}{*}{$\mathbf{4}$} & Print and electronic media & 19 & 24 & 83 & 61 \\
\hline & $(12)$ & $(43)$ & $(31)$ \\
\hline & Total mean & 26 & $(9)$ & $(20)$ & $(61)$ \\
\hline
\end{tabular}

than most people will believe. One third (37\%) agreed that living near the home of a person with mental illness does not endanger life, and nearly two thirds (61\%) agreed that people with mental illness are more dangerous than the general population. The majority (68\%) agreed that mental health facilities should be kept out of residential areas and three quarters (76\%) agreed that people with mental illness have the potential of committing violent crimes. Half (55\%) agreed that it is easy to recognize someone who once had a mental illness, and a similar number (52\%) agreed that people with mental illness should be locked away. Two thirds (66\%) strongly disagreed that people with mental illness were responsible for their illness. The total mean implies that, $55 \%$ of the participants has positive attitude while $45 \%$ had negative attitude towards mental disorder.

The data presented in Table 5 reveals that the mean score of students with positive attitude (31.38) is greater than the mean score of students with negative attitude (28.69) towards mental health disorder in secondary schools. Consequent upon the slight difference observed, the means were subjected to the t-test analysis in order to ascertain if the difference is significant (Table 5).

\section{Hypotheses Testing}

Hypothesis: There is no significant difference between students' with positive and negative attitudes towards mental health disorders in secondary schools. Table 6 shows that, the calculated t-value of 7.270 is greater than the critical t-value of 1.960 at 0.05 alpha level with 193 degrees of freedom. The alternative hypothesis which states that, there is a significant difference between students' with positive and negative attitudes towards mental health disorders in secondary schools is upheld.

\section{Discussion}

Findings from the study suggest that secondary school students have access to various forms of information, both negative and positive ideas about mental health issues. The type of information received contributed to the students' attitude and awareness about the disorder. Watson et al., [17] reported that providing correct information about mental health disorders can help reduce the fears, myths and negative beliefs that some people have about such disorders. Also, in another study [18] on strategies for changing attributions towards mental disorders, it was reported that students can become informed about mental health issues through discussions, talks, and awareness sessions in class and tutorials. Furthermore, the Canadian Centre for Addiction and Mental Health [24-26] confirmed that programs aiming at increasing young people's knowledge of mental health through education have shown positive results in reducing negative attitudes towards people with these disorders. Education is therefore a strong tool for enhancing knowledge and reducing negative attitudes towards mental health disorders.

The result shows that the majority of the respondents derived information about mental health disorders from the print media and their teachers, followed by movies, friends and family members that contributed to their attitudes to mental health disorders. The finding is similar to a study [21] on the impact of awareness programs in schools, which reported that teachers, peers, parents, news bulletin, health workers, print and electronic media could be the main sources of information. Evidence shows that programs aiming at increasing young people's knowledge of mental health through information have shown positive results in reducing negative attitudes towards people with mental health disorders $[17,21,27]$. This implies that there is a good channel of information for secondary school students. These findings are consistent with results from other studies that have found a positive association between better knowledge and understanding of the disease and less stigmatizing attitudes towards mental health disorders [19-20,27]. Therefore, improving the understanding of secondary school students about mental health disorders will not only affect the individuals who are enlightened but also society in general.

This finding supports the report of Adelman and Taylor [3] that students exhibits both positive and negative attitude towards those with mental health disorders in schools. It was reported [10] that negative attitude and perceptions can change when people have positive interactions with individuals with the disorder. A study [15] confirm that educating secondary school students about mental health disorders do not only affects their understanding of the disease but enables them to share their new understanding about the disease with their peers and family. In another study [16] reported that people who are knowledgeable about mental health disorders are less likely to endorse negative attitude, with stigma and discrimination being fueled by ignorance and misinformation. Furthermore, evidence has shown that attitudes and beliefs about mental health disorders are shaped by personal knowledge and experiences, and that when such attitudes and beliefs are expressed positively, they can result in supportive and inclusive behaviors $[19,21]$. It appears that many of the secondary school students had favorable attitudes towards mental health disorders in this study. Hence, educational programs need to target this receptive population in the knowledge that improving their perceptions of the disease will ensure a stronger societal de-stigmatization of mental health disorders as they develop into adults.

\section{Implications for Policy}

The results show varying attitudes and levels of awareness towards mental health disorder in secondary schools learners in the Niger Delta region of Nigeria. There is need to increase mental health literacy as a formal part of education among 
Table 4 Attitude towards mental health disorders $(n=195)$.

\begin{tabular}{|c|c|c|c|c|}
\hline S/no. & \multicolumn{1}{|c|}{ Item } & $\begin{array}{c}\text { Strongly } \\
\text { Agree } \\
\text { No (\%) }\end{array}$ & $\begin{array}{c}\text { Agree } \\
\text { No (\%) }\end{array}$ & $\begin{array}{c}\text { Strongly } \\
\text { Disagree } \\
\text { No (\%) (\%) }\end{array}$ \\
\hline No (\%)
\end{tabular}

Table 5 Summary of mean and standard deviation scores of students' with positive and negative attitudes towards mental health disorders.

\begin{tabular}{|c|c|c|c|}
\hline $\begin{array}{c}\text { Variables } \\
\begin{array}{c}\text { Students' with Positive } \\
\text { Attitude }\end{array}\end{array}$ & 107 & 31.38 & 2.350 \\
\hline $\begin{array}{c}\text { Students with Negative } \\
\text { Attitude }\end{array}$ & 88 & 28.69 & 2.818 \\
\hline Total & 195 & 30.17 & 2.895 \\
\hline
\end{tabular}

Table 6 T-test analysis of the difference between students' with positive and negative attitudes towards mental health disorders.

\begin{tabular}{|c|c|c|c|c|c|c|c|}
\hline Variables & N & X & SD & df & t-cal. & t-crit. & $\begin{array}{c}\text { Decision } \\
\text { at } p< \\
0.05\end{array}$ \\
\hline $\begin{array}{c}\text { Students' with Positive } \\
\text { Attitude }\end{array}$ & 107 & 31.38 & 2.35 & 193 & 7.270 & 1.960 & $*$ \\
\hline $\begin{array}{c}\text { Students with Negative } \\
\text { Attitude }\end{array}$ & 88 & 28.69 & 2.82 & - & - & - & - \\
\hline \begin{tabular}{l} 
* Significant at $p<0.05$ alpha level; $N=195$ \\
\hline
\end{tabular}
\end{tabular}

young people, with an emphasis on teachers, parents and other stakeholders who can influence students' awareness on mental health disorder in the schools environment.

\section{Limitations of the Study}

The use of a single Local Government Area (LGA) out of the eight LGA in the State makes it difficult to generalize the findings outside the study area, for which a wider population study is suggested.

\section{Conclusion}

The study shows the presences of both positive and negative attitude towards mental health disorders among secondary school students. Adolescence is regarded as a strategically important time for implementing anti-stigma interventions, as the attitude and values of young people tend to influence society. It is therefore important to address negative attitudes early to ensure positive changes. The need for training interventions is suggested to target this receptive population in the belief that improving perception of mental health disorder will discourage the stigma associated with the disorder. Secondary schools are important sites for mental health education campaigns that will provide accurate information, and thereby improve the knowledge and attitude of future generation and dispel the fear and false beliefs often associated with mental health disorders. 


\section{References}

1 World Health Organization (2010) Mental health and development. World Health Organ, Geneva.

2 Belfer ML (2008) Child and adolescent mental disorders: the magnitude of the problem across the globe. J Child Psychol Psychiatry 49: 226-236.

3 Adelman HS, Taylor L (2006) Mental health in schools and public health. Public Health 121: 294-298.

4 Patel V, Flisher AJ, Hetrick S, McGorry P (2007) Adolescent Health 3 - Mental health of young people: a global public-health challenge. Lancet 369: 1302-1313.

5 Kessler RC, Berglund P, Demler O, Jin R, Merkangas KR, et al. (2005) Lifetime prevalence and age-of-onset distributions' of DSM-IV disorders in the national comorbidity survey replication. Arch Gen Psychiatry 62: 593-602.

6 Brown SA (2008) Factors and measurement of mental illness stigma: a psychometric examination of the Attribution Questionnaire. Psychiatr Rehabil J 32: 89-94.

7 Sartorius N, Schulze H (2005) Reducing the Stigma of Mental Illness: A Report from a Global Programme of the World Psychiatric Association. Cambridge University Press.

8 Kennedy V, Belgamwar RB (2014) Impact of work experience placements on school students' attitude towards mental illness. Psychiatric Bulletin. 38: 159-163.

9 Cook JA (2006) Employment barriers for persons with psychiatric disabilities: Update of a report for the residents commission. Psychiatr Serv 57: 1391-1405.

10 Corrigan P (2004) How stigma interferes with mental health care. American Psychologist 59: 614-625.

11 Romer D, Bock M (2008) Reducing the stigma of mental illness among adolescents and young adults: the effects of treatment information. J Health Commun 13: 742-758.

12 Corrigan PW, Shapiro JR (2010) Measuring the impact of programs that challenge the public stigma of mental illness. Clin Psychol Rev 30: 907-922.

13 Kohn R, Saxena S, Levav I, Saraceno B (2004) The treatment gap in mental health care. Bull of World Health Organ. 82: 858-866.

14 Prince M, Patel V, Saxena S, Maj M, Maselko J, et al. (2007) No Health without Mental Health. Lancet 370: 859-877.
15 Naylor PB, Cowie HA, Walters SJ, Talamelli L, Dawkins J (2009) Brit J Psychiatr 194: 365-370.

16 Al-Naggar (2013) Attitudes towards persons with mental illness among university students. ASEAN Journal of Psychiatry 14.

17 Watson AC, Otey E, Westbrook AL (2004) Changing middle schooler's attitudes about mental illness through education. Schizophr Bull 30 563-572.

18 Corrigan PW, River PL, Lundin R, Penn DL, Uphoff-Wasowski K, et al. (2001) Three strategies for changing attributions about severe mental illness. Schizophr Bull 27: 187-195.

19 Del Casale A, Manfredi G, Kotzalidis GD, Serata D, Rapinesi C, et al. (2013) Awareness and education on mental disorders in teenagers reduce stigma for mental illness: a preliminary study. J Psychopathol 19: 208-212.

20 Pejović MM, Lečić TD, Tenjović L, Popović DS, Draganić GS (2009) Changing attitudes of high school students towards peers with mental health problems. Psychiatria Danubina. 21: 213-219.

21 Pinfold V, Stuart H, Thornicroft G, Arboleda- Flórez J (2005) Working with young people: the impact of mental health awareness programmes in schools in the UK and Canada. World Psychiatry. 4: S1.

22 Boyle MJ, Williams B, Brown T (2010) Attitudes of undergraduate health science students towards patients with intellectual disability, substance abuse, and acute mental illness: A cross-sectional study. BMC Medical Education. 10: 1-8.

23 Mahto RK, Verma PK, Verma AN, Singh AR, Chaudhury S, et al. (2009) Students' perception about mental illness. India Psychiatry Journal 18: 92-96.

24 Burra P, Kalin R, Leichner P, Waldron JJ, Handforth JR, et al. (1982) The ATP 30 -a scale for measuring medical students' attitudes to psychiatry. Medical Education, 16: 31-38.

25 Green N, Thorogood N (2004) Qualitative methods for health research. Sage London.

26 Centre for Addiction and Mental Health, Canadian Mental Health Association (2001) Talking about mental illness: A guide for developing an awareness program for youth. Teacher's resource. Toronto: Centre for addiction and mental health.

27 Gudmundsdottir DG (2002) A study of adolescents' attitudes towards mental health: The Icelandic mental health promotion project. Int $J$ Ment Health Promot 1: 32-35. 